\begin{tabular}{|c|l|}
\hline Title & $\begin{array}{l}\text { Effects of growth conditions on the size and density of self-assembled InA IA s/A IGaA squantum dots grown on GaA s } \\
\text { by molecular beam epitaxy }\end{array}$ \\
\hline Author(s) & Lu, X. M.; Izumi, Y.; Koy ama, M.; Nakata, Y.; A dachi, S.; Muto, S. \\
\hline Citation & $\begin{array}{l}\text { Journal of Crystal Growth, 322(1), 6-9 } \\
\text { https:/doi.org/10.1016/.jcrysgro.2011.02.034 }\end{array}$ \\
\hline Issue Date & 2011-05-01 \\
\hline Doc URL & http://hdl.handle.net/2115/45603 \\
\hline Type & article (author version) \\
\hline File Information & JCG322-1_6-9.pdf \\
\hline
\end{tabular}

Instructions for use 


\title{
Effects of growth conditions on the size and density of self-assembled InAIAs/AIGaAs quantum dots grown on GaAs by molecular beam epitaxy
}

\author{
X. M. Lu ${ }^{a}$, Y. Izumi ${ }^{a}$, M. Koyama ${ }^{a}$, Y. Nakata ${ }^{b}$, S. Adachi ${ }^{a}$, and S. Muto ${ }^{a}$ \\ a Department of applied physics, Graduate School of Engineering, Hokkaido University, Sapporo, Hokkaido 060-8628, Japan \\ ${ }^{\mathrm{b}}$ Fujitsu Laboratories Ltd., 10-1 Morinosato-wakamiya, Atsugi 243-0197, Japan
}

\section{Abstract}

The effects of growth conditions on the size and density of self-assembled InAIAs/AIGaAs quantum dots (QDs) grown on GaAs by molecular beam epitaxy (MBE) were studied, with an emphasis on their use for single QD spectroscopy. The effects of substrate temperature and growth rate on the density and size were found to be quite similar to those of InAs QDs on GaAs. The effect of coverage, however, was different. Although the density was relatively high as compared to that of InAs QDs, it was reduced to $1 \times 10^{10} \mathrm{~cm}^{-2}$ under an optimized condition. This density is compatible with single QD spectroscopy with the help of a certain nanofabrication technique for areal restriction.

Key words: A1. Reflection high energy electron diffraction; A1. Atomic force microscopy; A3. Quantum dots; A3. Molecular beam epitaxy; B2. Semiconducting III-V materials

\section{Introduction}

Of late, spintronics applications of semiconductor quantum dots (QDs) have attracted considerable attention. We have been studying spintronics [1-8] of single InAIAs/AIGaAs QDs for quantum information processing such as quantum computing and quantum media conversion [9]. Low-density QDs are preferred for single dot spectroscopy, and several studies have been conducted on self-assembled InGaAs or InAs QDs, which have a low density of $1 \times 10^{9} \mathrm{~cm}^{-2}$ $[10,11]$. InAIAs QDs are at a disadvantage in this respect, since their density tends to be high. The high density could probably be due to the short surface diffusion of Al because of its high bonding energy with As. The advantage of InAIAs QDs, however, is that they can have a luminescence of $0.75 \mu \mathrm{m}$ at which the sensitivity of a Si CCD is maximum. With the help of current nanofabrication technologies, a dot density of $1 \times 10^{10} \mathrm{~cm}^{-2}$ can be achieved, which is acceptable if we can restrict the measurement area to the sub-micrometer range (300 500 nm) by mesa etching or masking. Then, ten dots in the area can be selected for spectroscopy, where an individual peak corresponds to a single dot.

In this study, we examined the effects of growth conditions on the size and density of self-assembled InAIAs QDs grown on AIGaAs by molecular beam epitaxy (MBE). We compared the effects with those for InAs QDs. We obtained QDs with a density of $1 \times 10^{10} \mathrm{~cm}^{-2}$ and a luminescence of around $0.75 \mu \mathrm{m}$ for an optimized condition.

\section{Experiments}

Figure 1 shows the structure grown by MBE on semi-insulating GaAs (001) substrates. The $\operatorname{In}_{0.7} \mathrm{Al}_{0.3} \mathrm{As} \mathrm{QDs}$ were grown on a layer of $\mathrm{Al}_{0.35} \mathrm{Ga}_{0.65} \mathrm{As}$. The QDs were grown with an $\mathrm{As}_{4}$ pressure of $6 \times 10^{-6}$ Torr and a temperature of $T_{s}$. After the growth, the substrate was held for 1 min at $T_{s}$ before the overgrowth of the second $\mathrm{Al}_{0.35} \mathrm{Ga}_{0.65}$ As layer. The InAIAs QDs were grown 
again for observation by atomic force microscopy (AFM).

Fig. 1 approx. here

\section{Effects of growth condition on density and size of QDs}

Fig. 2 approx. here

Figure 2 shows the effects of substrate temperature and growth rate on the density and the diameter of QDs for a fixed "relative" coverage of $\theta / \theta_{3 D}=1$.3. Here, $\theta$ is the coverage determined by the growth rate and the growth time, and $\theta_{3 \mathrm{D}}$ is the coverage at 2D-3D transition, which is defined by the transition of the reflection high-energy electron diffraction (RHEED) pattern from streaky to spotty. As the substrate temperature increases, the diameter increases and the density decreases. Also, as the growth rate decreases, the diameter increases and the density decreases. This tendency is the same as that observed for InAs QDs [12-14]. In the case of InAs QDs, this is interpreted as follows: as the temperature is increased, the surface migration of In atoms is enhanced and the distance between In atoms which have gathered to form a single dot is increased, resulting in larger dots with lower densities. A reduction in the growth rate shows the same tendency that is shown by an increase in the temperature. Our results indicate that the same mechanism has worked for our InAIAs QDs. We note here, the interdiffusion of In-Ga which increases with temperature can be present in our growth as in InAs on GaAs [15, 16]. As shown in Fig. 2(a), a QD density of $1 \times 10^{10} \mathrm{~cm}^{-2}$ is obtained with a high $\mathrm{T}_{\mathrm{s}}=520^{\circ} \mathrm{C}$ and a low growth rate of $0.0125 \mathrm{ML} / \mathrm{s}$

\section{Fig. 3 approx. here}

Figure 3 shows the photoluminescence $(\mathrm{PL})$ spectra from QD ensemble at $10 \mathrm{~K}$ excited by $488 \mathrm{~nm}$ radiation from Ar laser. The small peak around $830 \mathrm{~nm}$ is due to the GaAs substrate. The main peak is near $750 \mathrm{~nm}$, which is optimum for the single dot spectroscopy. The full width at half maximum (FWHM) is $163.6 \mathrm{meV}$, which is much wider than $30-40$ meV of our typical InAs QDs [17].

\section{Effect of coverage on density and size of QDs}

Fig. 4 approx. here

Figure 4 shows the effects of the coverage on the density and size of a QD. Neither the diameter nor the density changed as the coverage was increased above $\theta / \theta_{3 \mathrm{D}}=1$.1. However, the height increased as the coverage was increased. In the case of InAs QDs, it has been reported that the height was saturated as the coverage was increased. For comparison, we grew InAs/GaAs QDs and InAIAs/AIGaAs QDs under the same conditions (growth rate : 0.05ML/s, $\mathrm{T}_{\mathrm{s}}$ :

$\left.480^{\circ} \mathrm{C}, \quad \theta / \theta_{3 \mathrm{D}}: 1.3\right)$

\section{Fig. 5 approx. here}

Figure 5 shows the result of AFM measurements. Giant dots with a volume much larger than the QDs are seen in InAs as shown in Fig. 5(a). These giant dots are hardly seen in InAIAs despite the higher density and the shorter distances between dots. This suggests that an increase in the coverage is spent for an increase in height in InAIAs, and it is spent for the 
formation of giant dots in InAs.

\section{Dependence of 2D-3D transition time on growth conditions}

\section{Fig. 6 approx. here}

Figure 6 shows the relation between the substrate temperature and the 2D-3D transition time, $t_{3 D}$, which is defined by the transition of the RHEED pattern from streaky to spotty. The $t_{3 D}$ increases as the substrate temperature, $T_{s}$ increases, and this tendency is enhanced as the growth rate decreases. Let us discuss this in terms of In re-evaporation which decreases the coverage and increases the $\mathrm{Al}$ content of InAlAs, both resulting in increased $t_{3 \mathrm{D}}$.

We included the effects of In re-evaporation by assuming the InAs growth rate, $G_{R}{ }^{\ln A s}$ in the following form.

$$
G_{R}^{I n A s}=F-A \exp \left(-\frac{E_{b}}{k T}\right)=F\left\{1-\frac{A}{F} \exp \left(-\frac{E_{b}}{k T}\right)\right\}
$$

Here, $F$ is the flux of In atoms, $E_{\mathrm{b}}$ is the activation energy of In re-evaporation, and $A$ is a proportionality constant. The coefficient $A$ on the right hand side of eq. 1 includes the effect of the growth rate difference. The ratio of flux loss due to re-evaporation is inversely proportional to the flux as seen in the last formula of eq.1.

\section{Fig. 7 approx. here}

The temperature dependence of the growth rate of InAs has already been reported [18]. By numerical fitting we deduced $A=1.9 \times 10^{11} \mathrm{ML} / \mathrm{s}$ and $E_{\mathrm{b}}=2.25 \mathrm{eV}$. We neglected the possibility of $\mathrm{Al}$ re-evaporation because of the high Al-As bonding energy. Figure 7 shows the 2D-3D transition thickness of InAIAs thus obtained as a function of $A$ mole fraction, $x$ of $\operatorname{In}_{1-x} A l_{x} A s$. Here the thickness was given by the $t_{3 D}$ multiplied by the growth rate of InAIAs $\left(G_{R}{ }^{I n A s}+G_{R}{ }^{A I A s}\right)$ and $x$ was given by $G_{R}{ }^{A 1 A s} /\left(G_{R}{ }^{\text {InAs }}+G_{R}{ }^{\text {AlAs }}\right)$. Figure 7 compares our result with the data reported by Leon and co-workers [19]. The data that did not consider the re-evaporation is also shown by triangles, for comparison.

First, we note that our corrected result (circles) at $510^{\circ} \mathrm{C}$ fits closely with the $530^{\circ} \mathrm{C}$ curve by Leon. Second, the gradient of our corrected data is quite different from that of Leon's. These indicate that the $T_{s}$ dependence of $t_{3 D}$ in Fig. 6 can not be well-explained simply by the In re-evaporation and other mechanisms essentially dependent on $T_{s}$ is working such as In migration and In-Ga interdiffusion. This is in contrast with the report of InAs QD [18] in which the $T_{S}$ dependence of $t_{3 D}$ was explained by the re-evaporation.

We give some comments on the parameter $\theta / \theta_{3 \mathrm{D}}$, or more precisely (growth time of InAlAs)/ $t_{3 D}$ used in Fig. 2. The above argument tells us that we cannot fix the coverage by fixing $\theta / \theta_{3 \mathrm{D}}$. Therefore, discussing the dependence of $Q D$ density and diameter on $T_{s}$ and $G_{R}$ by fixing $\theta / \theta_{3 D}$, appear meaningless. Nevertheless, we have obtained a reasonable dependence on $T_{s}$ and $G R$. This is because the density and the diameter are saturated for $\theta / \theta_{3 \mathrm{D}}=1.3$, as shown in Fig.4.

\section{Summary}

We have investigated the effects of growth conditions on the size and density of 
self-assembled InAIAs QDs grown by MBE on the semi-insulating GaAs (001) substrates. It has been observed that the diameter increases and the density decreases with increasing substrate temperature or with decreasing growth rate. We acquired a dot density of $1 \times 10^{10} \mathrm{~cm}^{-2}$ for an optimized condition, which is compatible with single dot spectroscopy. We conclude that the change in the 2D-3D transition time is not simply explained by the In re-evaporation.

Acknowledgements: We would like to thank Y. Sakaue for his help with the photoluminescence characterizations.

\section{References}

[1] R. Kaji, S. Adachi, T. Shindo, S. Muto, Phys. Rev. B 80 (2009) 235334.

[2] R. Kaji, S. Adachi, H. Sasakura, S. Muto, Phys. Rev. B 77 (2008) 115345.

[3] H. Sasakura, R. Kaji, S. Adachi, S. Muto, Appl. Phys. Lett. 92 (2008) 041915.

[4] H. Sasakura, S. Adachi, S. Muto, S. Hirose, H. Z. Song, M. Takatsu, J. Appl. Phys. 103 (2008) 103530.

[5] S. Adachi, H. Sasakura, N. Yatsu, R. Kaji, S. Muto, Appl. Phys. Lett. 91 (2007) 16190.

[6] R. Kaji, S. Adachi, H. Sasakura, S. Muto, Appl. Phys. Lett. 91 (2007) 261904.

[7] T. Yokoi, S. Adachi, H. Sasakura, S. Muto, H. Z. Song, T. Usuki, S. Hirose, Phys. Rev. B 71 (2005) 041307.

[8] T. Watanuki, S. Adachi, H. Sasakura, S. Muto, Appl. Phys. Lett. 86 (2005) 063114.

[9] S. Muto, S. Adachi, T. Yokoi, H. Sasakura, I. Suemune, Appl. Phys. Lett. 87 (2005) 112506.

[10] R. Songmuang, S. Kiravittaya, M. Sawadsaringkarn, S. Panyakeow, O. G. Schmidt, J. Crystal Growth 251 (2003) 166.

[11] B. Alloing, C. Zinoni, V. Zwiller, L. H. Li, C. Monat, M.Gobet, G. Buchs, A, Fiore, E. Pelucchi, E. Kapon, Appl. Phys. Lett. 86 (2005) 101908.

[12] T. Kaizu, K, Yamaguchi, Jpn. J. Appl. Phys. 40 (2001) 1885.

[13] Y. Nakata, Y. Sugiyama, M. Sugawara, Semiconductor and semi-metals, Academic, San Diego, 1999.

[14] V. G. Dubrovskiia, G. E. Cirlinb, Yu. G. Musikhina, Yu. B. Samsonenkob, A. A. Tonkikha, N. K. Polyakovb, V. A. Egorovb, A. F. Tsataul'nikova, N. A. Krizhanovskayaa, V. M. Ustinova, P. Wernerc, J. Crystal Growth 267 (2004) 47.

[15] T. Haga, M. Kataoka, N. Matsumura, S. Muto, Y. Nakata, N, Yokoyama, J. Appl. Phys. 36 (1997) 1113-1115.

[16] I. Kegel, T. H Metzger, A. Lorke, J. Peisl, J. stangl, G. Bauer, J. M. Garcia, P. M. Petroff, Phys. Rev. Lett. $85(2000) 1694$.

[17] H. Sasakura, S.Kayamori, S.Adachi, S, Muto, J. Appl. Phys.102 (2007) 013515.

[18] F. Patella, F. Arciprete, M. Fanfoni, A. Balzarotti, Appl. Phys. Lett. 88 (2006) 161903.

[19] R. Leon, S. Fafard, D. Leonard, J. L. Merz, P. M. Petroff, Appl. Phys. Lett. 67 (1995) 521.

\section{Figure Captions}

FIG. 1. Structure of InAIAs quantum dots (QDs) grown on a layer of AIGaAs. The QDs on the top have been grown for observation by atomic force microscopy (AFM).

FIG. 2. Density (a) and diameter (b) of InAIAs QDs as a function of the growth temperature. $\theta$ is the coverage determined by the growth rate and growth time, and $\theta_{3 \mathrm{D}}$ is the coverage at $2 \mathrm{D}-3 \mathrm{D}$ 
transition, which is defined by the transition of the RHEED pattern from streaky to spotty.

FIG. 3. The photoluminescence (PL) spectra due to optimized growth from QD ensemble at $10 \mathrm{~K}$ excited by $488 \mathrm{~nm}$ radiation from an Ar laser.

FIG. 4. Density (a), diameter (b), and height (c) of InAIAs QDs as a function of $\theta / \theta_{3 D}$.

FIG. 5. AFM image of InAs/GaAs QDs (a) and InAIAs/AIGaAs QDs (b). Both of them were grown under the same conditions (growth rate: $0.05 \mathrm{ML} / \mathrm{s}, \mathrm{T}_{\mathrm{s}}: 480^{\circ} \mathrm{C}, \theta / \theta_{3 \mathrm{D}}: 1.3$ ).

FIG. 6. The transition time ( $\left.\mathrm{t}_{3 \mathrm{D}}\right)$ of RHEED pattern changes from streaky to spotty as a function of the substrate temperature $\left(T_{s}\right)$.

FIG. 7. The critical thickness compares with the data reported by $R$. Leon et al. The thickness was given by the $t_{3 p}$ multiplied by the growth rate of InAlAs $\left(G_{R}{ }^{\text {IAs }}+G_{R}\right.$ AlAs $)$ and $x$ was given by $G_{R}^{A I A S} /\left(G_{R}{ }^{I n A S}+G_{R}{ }^{3 P A S}\right)$. Inset shows an enlargement of the boxed region. The data with (without) considering In re-evaporation has been shown as circles (triangles). 


\section{$\mathrm{In}_{0.7} \mathrm{Al}_{0.3} \mathrm{As} \mathrm{QDs}$}

$\mathrm{Al}_{0,35} \mathrm{Ga}_{0.65} \mathrm{As}$

$\mathrm{Al}_{0.35} \mathrm{Ga}_{0.65} \mathrm{As}$

\section{GaAs}




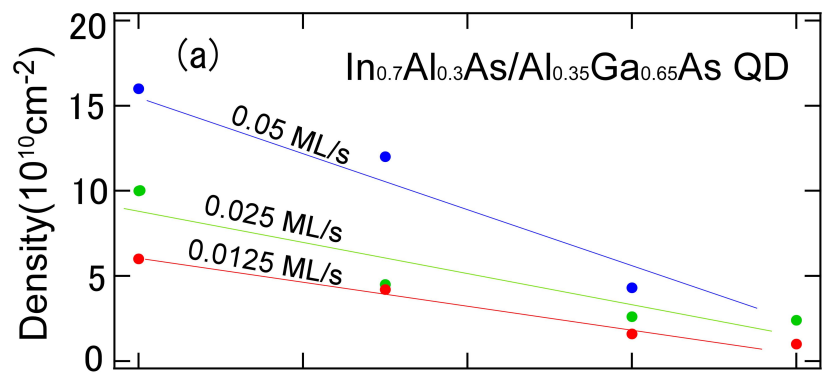

(b)

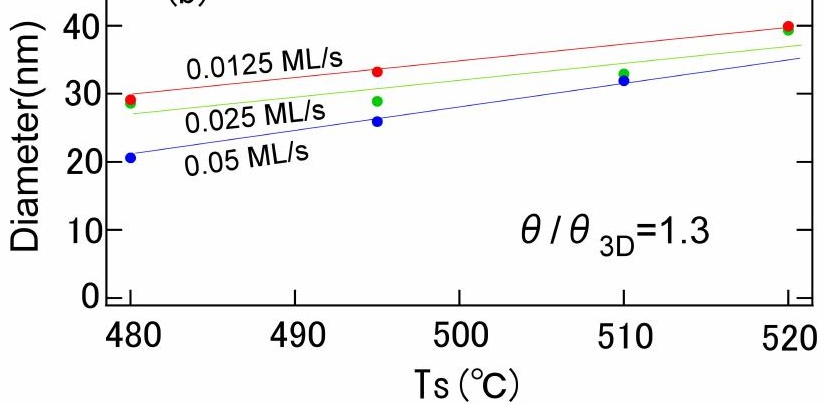




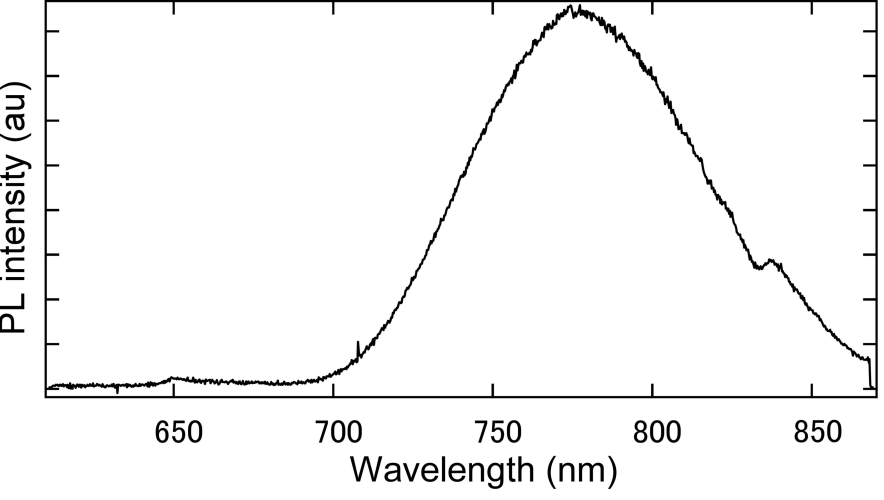



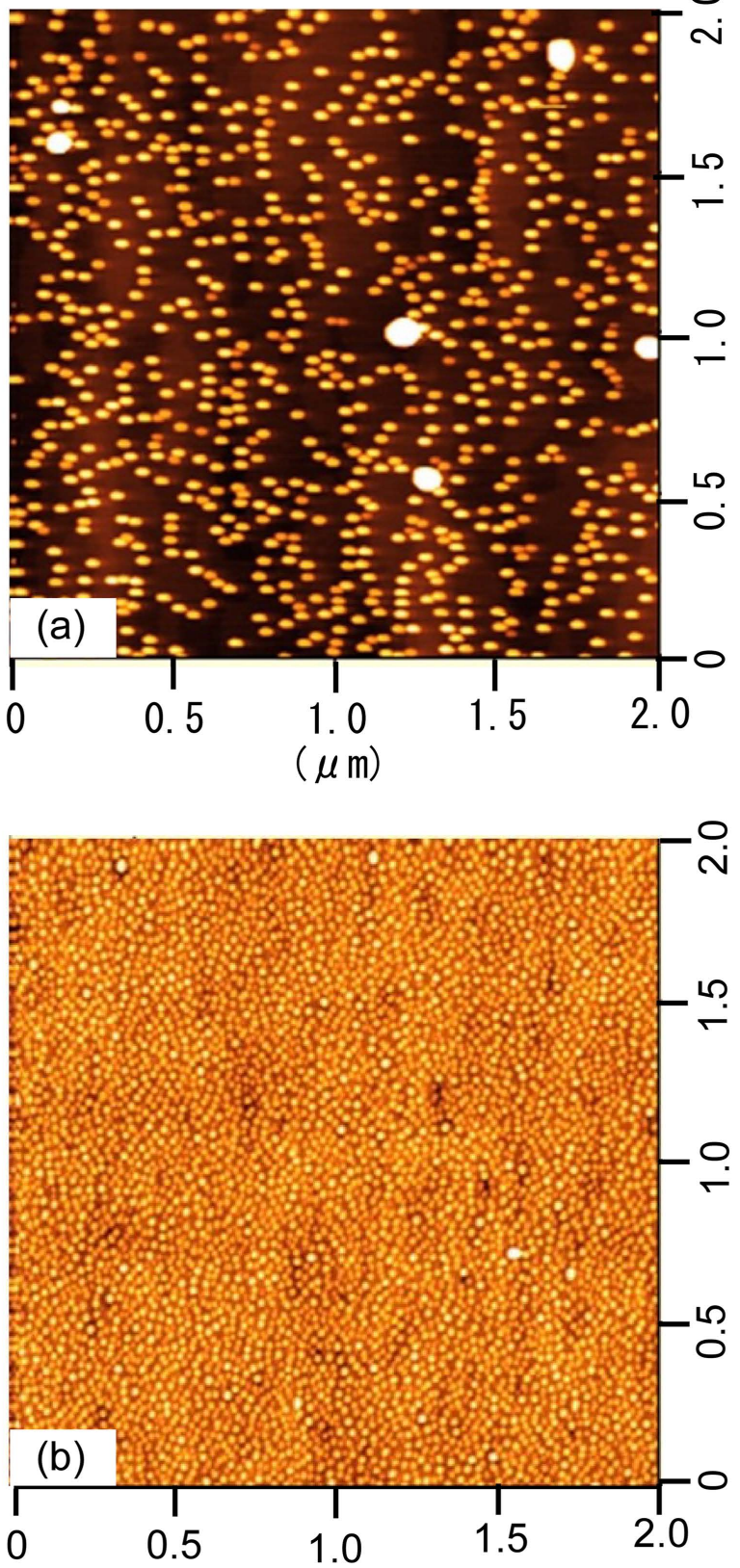


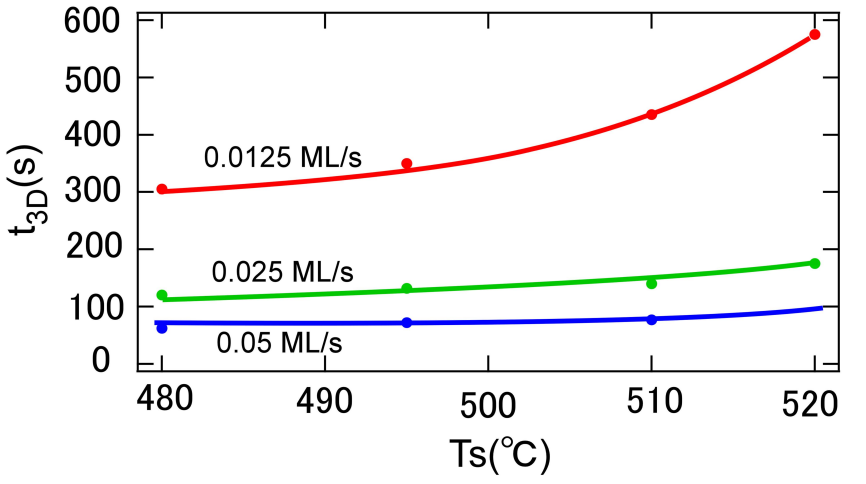


